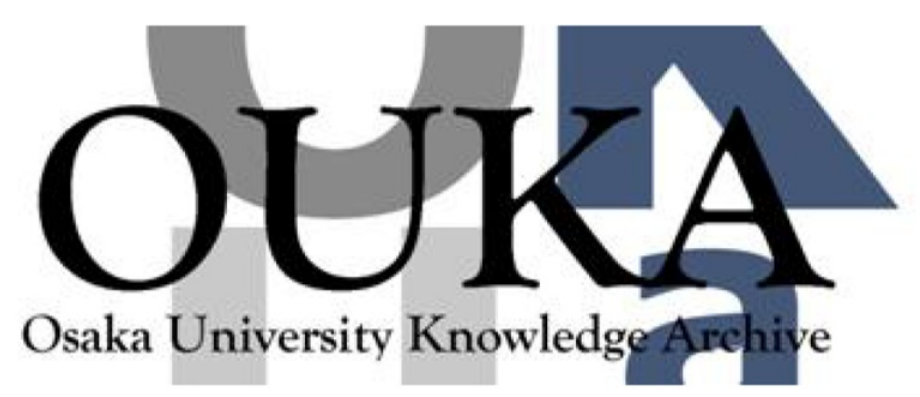

\begin{tabular}{|c|c|}
\hline Title & $\begin{array}{l}\text { Solvent and Temperature Effects on the Chiral } \\
\text { Aggregation of Optically Active } \\
\text { Poly(dialkylsilane)s Confined in Microcapsules }\end{array}$ \\
\hline Author (s) & $\begin{array}{l}\text { Terao, Ken; Mori, Yasutaka; Dobashi, Toshiaki } \\
\text { et al. }\end{array}$ \\
\hline Citation & Langmui r. $20(2)$ p. 306-p. 308 \\
\hline Issue Date & $2003-12-12$ \\
\hline oaire:version & AM \\
\hline URL & https://hdl. handle. net/11094/81827 \\
\hline rights & $\begin{array}{l}\text { This document is the Accepted Manuscript } \\
\text { version of a Published Work that appeared in } \\
\text { final form in Langmuir, } \odot \text { American Chemical } \\
\text { Society after peer review and technical editing } \\
\text { by the publisher. To access the final edited } \\
\text { and published work see } \\
\text { https://doi.org/10.1021/La0302798. }\end{array}$ \\
\hline Note & \\
\hline
\end{tabular}

Osaka University Knowledge Archive : OUKA

https://ir. Library. osaka-u. ac. jp/

Osaka University 


\title{
Solvent and Temperature Effects on the Chiral Aggregation of Optically Active Poly(dialkylsilane)s Confined in Microcapsules
}

\author{
Ken Terao, *广 Yasutaka Mori, and Toshiaki Dobashi
}

Department of Biological and Chemical Engineering, Faculty of Engineering, Gunma University, 1-5-1, Tenjin-cho, Kiryu, Gunma 376-8515, Japan.

\section{Takahiro Sato}

Department of Macromolecular Science, Osaka University, 1-1, Machikaneyama-cho, Toyonaka, Osaka 560-0043, Japan.

\section{Akio Teramoto}

Department of Applied Chemistry, Faculty of Science and Engineering, Ritsumeikan University, Nojihigashi 1-1-1, Kusatsu, Shiga 525-8577, Japan.

\section{Michiya Fujiki}

Graduate School of Materials Science, Nara Institute of Science and Technology (NAIST), 8916-5 Takayama, Ikoma, Nara 630-0101, Japan.

E-mail: terao@bce.gunma-u.ac.jp (K. Terao)

Running head: Polysilane Aggregates Confined in Microcapsules

* To whom correspondence should be addressed. E-mail: terao@bce.gunma-u.ac.jp.

$\dagger$ Present address: Department of Chemistry, University of Tennessee, 552 Buehler Hall, Knoxville, Tennessee 37996.

\$Also at CREST, Japan Science and Technology Corporation.

ABSTRACT To obtain optically active polysilane aggregates consisting of an appropriate number of polysilane molecules, polysilane aggregates were prepared into poly(ureaurethane) microcapsules and their bisignate circular dichroism signals around $320 \mathrm{~nm}$ was observed at three different temperatures. The size of aggregates and the chiroptical properties of polysilanes could be fixed by the preparation temperature. The memorized chiroptical property was eliminated only when the aggregation was disintegrated. This methodology is suitable to control the chiroptical properties of polysilanes.

Chiral polymers are expected to be applied for miniature-scale optical parts because the helical structure of some chiral polymers are sensitively affected by the environment around the polymers, e.g., solvent or temperature. ${ }^{1}$ Chiroptical polysilanes in solution have remarkable circular dichroism (CD) on the basis of the helical structure of their main chain and the helical structure can be easily controlled when appropriate side chains are chosen. ${ }^{2}$ Recently, Nakashima et al. ${ }^{3}$ found that the CD signal from optically active polysilane aggregates was much stronger than those from polysilanes in solution. Furthermore, they discovered thermo-driven CD switching phenomena of polysilane in an appropriate mixture of a good solvent and a precipitant. It seems that the aggregate is more suitable for the use as optical parts than the solution.

In this study, well-fractionated samples of F42 of poly[n-hexyl-(S)-3-methylpentylsilane] (1) and D2MBS-2 of poly[n-decyl-( $S)$-2-methylbutylsilane] (2) were chosen. ${ }^{4,5}$ Their chemical structures were shown in Figure 1. The CD strength of the polymer 1 remarkably depends on temperature around $0^{\circ} \mathrm{C}$ 
whereas the polymer 2 is almost independent of it. The weight-average number $N_{\mathrm{w}}$ of Si units were reported to be 1290 and 2970 for F42 and D2MBS-2, respectively. These samples had been well fractionated and the ratio of $N_{\mathrm{w}}$ to number-average number $N_{\mathrm{n}}$ of Si had been estimated to be 1.10 for both samples. As shown in Figure 2, the CD spectra for polymer 1 (F42) in tetrahydrofuran (THF) $(c=$ $\left.1 \times 10^{-5} \mathrm{~g} \mathrm{~cm}^{-3}\right)$ at 20 and $-10^{\circ} \mathrm{C}$ are much stronger than those at $50^{\circ} \mathrm{C}$ and those in isooctane, a good solvent, at the same temperature. ${ }^{2(\mathrm{~b}), 4(\mathrm{~b})}$ It is suggested that these remarkable CD signals observed at 20 and $-10^{\circ} \mathrm{C}$ are ascribed to an exciton couplet of chirally aggregated polysilanes. Indeed, these CD signals became larger with time at $-10^{\circ} \mathrm{C}$; CD signals observed 30 minutes later were twice as large as the initial one, and significant precipitations were observed by naked eyes one hour later. On the other hand, THF solution of polymer 2 (D2MBS-2) $\left(c=1 \times 10^{-5} \mathrm{~g} \mathrm{~cm}^{-3}\right)$ at $-10^{\circ} \mathrm{C}$ yielded aggregates, which developed too quickly to observe their CD spectra, whereas no aggregates were observed for the solutions at 20 and $50{ }^{\circ} \mathrm{C}$. These results suggest that the aggregates should be wrapped in order not to generate too big aggregates when we investigate their optical properties, e.g. the absorption or the CD spectra.

To control the size of the aggregates, we tried to confine the solution of optically active polysilanes in microcapsules and to impregnate the microcapsules with another solvent or non-solvent after encapsulation as shown in Figure 1. Poly(ureaurethane) (PUU) microcapsules having polyethyleneglycols on the surface ${ }^{6}$ are suitable for this purpose because it can be dispersed in various solvents e.g. alcohols and ethers. Our group found that the structure of a PUU microcapsule is very close to the spherical shell ${ }^{7}$ and the wall membrane can be permeable to small molecules. ${ }^{8}$ It is therefore expected that the polysilane aggregates can be prepared with the uniformed and programmable size, because the average number of polymer chains in a microcapsule can be controlled by the choices of concentration of polysilane and the size of microcapsules.

Each solution of the polysilane samples in isooctane $\left(2.0 \times 10^{-4} \mathrm{~g} \mathrm{~cm}^{-3}\right)$ were confined in PUU microcapsules in the manner described as follows. $20 \mathrm{~g}$ of polyethylene glycol monomethyl ether PEGME (average molecular weight: 5,000, Polyscience) dried in vacuum over night were dissolved into $40 \mathrm{~cm}^{3}$ of dried acetonitrile (Kanto) adding $4 \mathrm{~g}$ of molecular sieves 4A. After the mixture was stirred for 3 hours under dry nitrogen, $40 \mathrm{~g}$ of Takenate D160N $(70 \sim 80 \%$ ethyl acetate solution of trimethylolpropane carbamate with hexahydroxylylene diisocyanate TCHDI, Mitsui Takeda Chemical Co.) and $0.16 \mathrm{~cm}^{3}$ of Tin(II) 2-ethylhexanoate (Wako) was added to the mixture. The resulting mixture was stirred at room temperature for an hour and subsequently at $60^{\circ} \mathrm{C}$ for 22 hours in order to obtain an adduct of TCHDI and PEGME. ${ }^{6} 1.0 \mathrm{~g}$ of the mixture was added with $1.0 \mathrm{~g}$ of Takenate D160N and $1.0 \mathrm{~g}$ of isooctane solution of each polysilane sample to $3.0 \mathrm{~g}$ of ethyl acetate (Wako). After stirring, we added $10 \mathrm{~g}$ of water and immersed vigorously at 5,000 rpm by using an emulsifier (Excel Auto, Nihon Seiki Co.). The emulsion obtained was stirred at $50^{\circ} \mathrm{C}$ for $12 \mathrm{~h}$. Because the smell of these two solvents had disappeared during this stirring, it was confirmed that the most part of acetonitrile and ethyl acetate vaporized in this process. Spherical shell structure of the product was confirmed by the single-particle light scattering (SPLS) measurement in water and ethanol with our light scattering apparatus described in ref. 9. The number-average outer diameter and its standard deviation were determined respectively to be $2.0 \mu \mathrm{m}$ and $1.0 \mu \mathrm{m}$ by microscopic observation from more than 500 capsules. From a similar measurement, we found that the shape in both ethanol and tetrahydrofuran was spherical and the size was almost equal to that in water. The number-average mass of the polysilane in a microcapsule was estimated to be $5.4 \times 10^{-16} \mathrm{~g}$ from the outer diameter and the volume fraction of isooctane solution in a microcapsule being 0.63. Therefore, 1300 molecules of 1 or 450 molecules of 2 are contained in a microcapsule. The microcapsules including $\mathbf{1}$ and $\mathbf{2}$ are designated as MC1 and MC2, respectively.

In order to form polysilane aggregates in the microcapsules, $0.10 \mathrm{~cm}^{3}$ of the microcapsule suspension was poured into $10 \mathrm{~cm}^{3}$ of tetrahydrofuran $(\mathrm{THF})$ or ethanol $(\mathrm{EtOH})$ at two different temperatures $T_{\mathrm{p}}$ of $20^{\circ} \mathrm{C}$ or $-78^{\circ} \mathrm{C}$. After the suspensions were stirred for 20 minutes at each temperature, they were transferred into a quartz cell of $1.0 \mathrm{~cm}$ path length at room temperature $\left(20^{\circ} \mathrm{C}\right)$. No leak of the polysilanes from the capsule was confirmed by the UV absorbance of the supernatant isolated from each suspension being zero around $320 \mathrm{~nm}$ wavelength where the polysilanes 1 and 2 have a remarkable 
absorbance peak. ${ }^{4(b), 10}$ The supernatant could be easily separated because all microcapsules sank completely about ten days later. We note that the accumulating microcapsules could be dispersed again only by a gentle stir. CD measurements at the temperatures $T_{\mathrm{m}}$ of $-10,20$, and $50^{\circ} \mathrm{C}$ were made on a JASCO J720 spectropolarimeter combined with a Peltier temperature controller at a wavelength of the incident light between 260 and $360 \mathrm{~nm}$. To avoid the degradation of polysilanes by UV light, different suspensions were used at each measurement. These experimental conditions are the same as in our previous study, and it was confirmed that the polysilane did not degrade during the measurement. ${ }^{4(\mathrm{~b})}$

Figure 3(a) illustrates the $\mathrm{CD}$ spectra for $\mathrm{MC}-1$ in $\mathrm{THF}$ prepared at $T_{\mathrm{p}}=-78^{\circ} \mathrm{C}$. Significantly bisignate $\mathrm{CD}$ signals are shown for $T_{\mathrm{m}}=-10$ and $20^{\circ} \mathrm{C}$, and the curves are similar in shape to those for the THF solution of 1 , whereas no marked signal is observed at $T_{\mathrm{m}}=50^{\circ} \mathrm{C}$. The fact that the CD extrema are not observed only at $T_{\mathrm{m}}=50^{\circ} \mathrm{C}$ is consistent with those for THF solution of 1 without microcapsule. However, the $\mathrm{CD}$ signal for $\mathrm{MC}-1$ at $T_{\mathrm{m}}=-10^{\circ} \mathrm{C}$ is comparable to that at $20^{\circ} \mathrm{C}$ in contrast to the CD signal for THF solution not enclosed in microcapsules shown in Figure 2. This result suggests that the strong CD signal for THF solution at $T_{\mathrm{m}}=-10^{\circ} \mathrm{C}$ comes from aggregates comprising a large number of molecules and the chiral structure of the polysilane aggregates in microcapsules is almost independent of $T_{\mathrm{m}}$. The CD spectra poured into EtOH (a non-solvent of polymer 1) for $T_{\mathrm{p}}=-$ $78^{\circ} \mathrm{C}$ are shown in the panel (b) of Figure 3. Although the bisignate $\mathrm{CD}$ spectra are observed, the strength is almost independent of $T_{\mathrm{m}}$. This result supports the above suggestion.

Temperature dependence of the average value $\Delta \varepsilon_{305-310}$ of $\Delta \varepsilon$ between 305 and $310 \mathrm{~nm}$ is illustrated in Figure 4. The CD signals for MC-1 [panel (a)] in THF for $T_{\mathrm{m}}=50^{\circ} \mathrm{C}$ vanish because the aggregates of polymer 1 were dissolved without aggregates in this condition. On the other hand, all the data except these data for $T_{\mathrm{m}}=50^{\circ} \mathrm{C}$ in THF are almost independent of $T_{\mathrm{m}}$ and they depend significantly on $T_{\mathrm{p}}$. In other words, these aggregates memorize the structure determined by $T_{\mathrm{p}}$. Similar plots for $\mathrm{MC}-2$ are shown in panel (b). The chirality are the reverse to that for MC-1 although the CD spectra for both 1 and 2 in solution have a single plus signal. ${ }^{4(b), 10}$ MC-2 in THF has a significant CD spectra only at $10^{\circ} \mathrm{C}$. This result is consistent with the behavior of aggregation for polymer 2 in $\mathrm{THF}$ described above. ${ }^{11}$ On the other hand, the $\mathrm{CD}$ signals in $\mathrm{EtOH}$ have almost the same trend as that for MC-1.

In summary, we have succeeded in preparing optically active polysilane aggregates confined in microcapsules and measuring their CD signals at different temperatures. From the CD data, the aggregates memorized the structure determined by the temperature in preparation and the memory was eliminated only when the aggregates were disintegrated. The encapsulation method reported can thus be applied to control the chiroptical properties of the aggregates of other polymers and to investigate the molecular number dependence of the optical structure of polymer aggregates.

Acknowledgement. We thank Dr. Kimio Ichikawa of Fuji Photo Film Co. Ltd. for fruitful discussion and Ms. Akane Ohsawa and Dr. Takayuki Narita of Gunma University for their help on microscopic observation and SPLS. This research was partially supported by Japan Society for the Promotion of Science Grant-in-Aid for Exploratory Research, 13875119 and by Ministry of Education, Culture, Sports, Science, and Technology (MEXT) Grant-in-Aid for Young Scientists (B), 14750703.

\section{References and Notes}

(1) (a) Teramoto, A. Prog. Polym. Sci. 2001, 26, 667-720. (b) Green, M. M. A Model for How Polymers Amplify Chirality. In Circular Dichroism Principles and Applications, 2nd ed.; Berova, N., Nakanishi, K., Woody, R. W., Eds.; Wiley-VCH: New York, 2000; Chapter 17. (c) Nakano, T.; Okamoto, Y. Chem. Rev. 2001, 101, 4013-4038.

(2) (a) Fujiki, M. Macromol. Rapid. Commun. 2001, 22, 539-563. (b) Sato, T.; Terao, K.; Teramoto, A.; Fujiki, M. Polymer, 2003, 44, 5477-5495. (c) Fujiki, M.; Koe, J.; Terao, K.; Sato, T.; Teramoto, A.; Watanabe, J. Polym. J., 2003, 35, 297-344.

(3) Nakashima, H.; Fujiki, M.; Koe, J. R.; Motonaga, M. J. Am. Chem. Soc. 2001, 123, 1963-1969.

(4) (a) Terao, K.; Terao, Y.; Teramoto, A.; Nakamura, N.; Fujiki, M.; Sato, T. Macromolecules 2001, 34, 4519-4525. (b) ibid. 6519-6525.

(5) Natsume, T.; Wu, L.; Sato, T.; Terao, K.; Teramoto, A.; Fujiki, M. Macromolecules 2001, 34, 7899-7904.

(6) (a) Wakata, Y., Ichikawa, K. (Fuji Film Co.). Jpn. Kokai Tokkyo Koho 10 114,153, May 6, 1998. (b) U. S. Patent 5,916,680, June 29, 1999. 
(7) (a) Ichikawa, K. J. Appl. Polym. Sci. 1994, 54, 1321-1327. (b) Dobashi, T.; Yeh, F.-j.; Ying, Q.; Ichikawa, K.; Chu, B. Langmuir 1995, 11, 4278-4282. (c) Dobashi, T.; Yeh, F.-j.; Takenaka, M.; Wu, G.; Ichikawa, K.; Chu, B. J. Colloid Interface Sci. 1996, 179, 640-642. (d) Dobashi, T.; Furukawa, T.; Narita, T.; Shimofure, S.; Ichikawa, K.; Chu, B. Langmuir 2001, 17, 4525-4528.

(8) (a) Sato, T.; Yamamoto, T.; Shibako, S.; Ichikawa, K.; Dobashi, T. J. Membr. Sci. 2003, 213, $25-$ 31. (b) Chang, C. P.; Yamamoto, T.; Kimura, M.; Sato, T.; Ichikawa, K.; Dobashi, T. J. Controlled Release 2003, 86, 207-211. (c) Furukawa, T.; Hung, S.; Yamamoto, T.; Terao, K.; Ichikawa, K.; Dobashi, T. Trans. Mater. Res. Soc. Jpn. 2003, 28, XXXX-YYYY.

(9) Dobashi, T.; Narita, T.; Masuda, J.; Makino, K.; Mogi, T.; Ohshima, H.; Takenaka, M.; Chu, B. Langmuir 1998, 14, 745-749.

(10) (a) Fujiki, M. J. Am. Chem. Soc. 1994, 116, 6017-6018. (b) Fujiki, M. Appl. Phys. Lett. 1994, 65, 3251-3253.

(11) The data for MS-2 prepared in THF at $-78^{\circ} \mathrm{C}$ was not shown here because the aggregates disappeared when the suspension stored at $20^{\circ} \mathrm{C}$ after pouring into THF. Indeed, the CD spectra for this aggregate were almost the same as that prepared at $20^{\circ} \mathrm{C}$. 


\section{Figure caption}

Figure 1. Schematic representation of the process to prepare aggregates in a microcapsule and chemical structures of polysilanes 1 and 2 .

Figure 2. CD spectra for polymer 1 in THF at $-10{ }^{\circ} \mathrm{C}$ (open circles), $20{ }^{\circ} \mathrm{C}$ (triangles), and $50{ }^{\circ} \mathrm{C}$ (filled circles).

Figure 3. CD spectra for MC-1 prepared at $T_{\mathrm{p}}=-78^{\circ} \mathrm{C}$ and measured at $T_{\mathrm{m}}=-10{ }^{\circ} \mathrm{C}$ (open circles), $T_{\mathrm{m}}$ $=20^{\circ} \mathrm{C}$ (triangles), and $T_{\mathrm{m}}=50^{\circ} \mathrm{C}$ (filled circles). (a) Prepared in THF, (b) in EtOH.

Figure 4. Temperature dependence of $\Delta \varepsilon$ for $T_{\mathrm{p}}=-78{ }^{\circ} \mathrm{C}$ (filled symbols) or $T_{\mathrm{p}}=20{ }^{\circ} \mathrm{C}$ (open symbols) in $\mathrm{EtOH}$ (triangles) or in THF (circles). (a) MC-1, (b) MC-2. 
1.
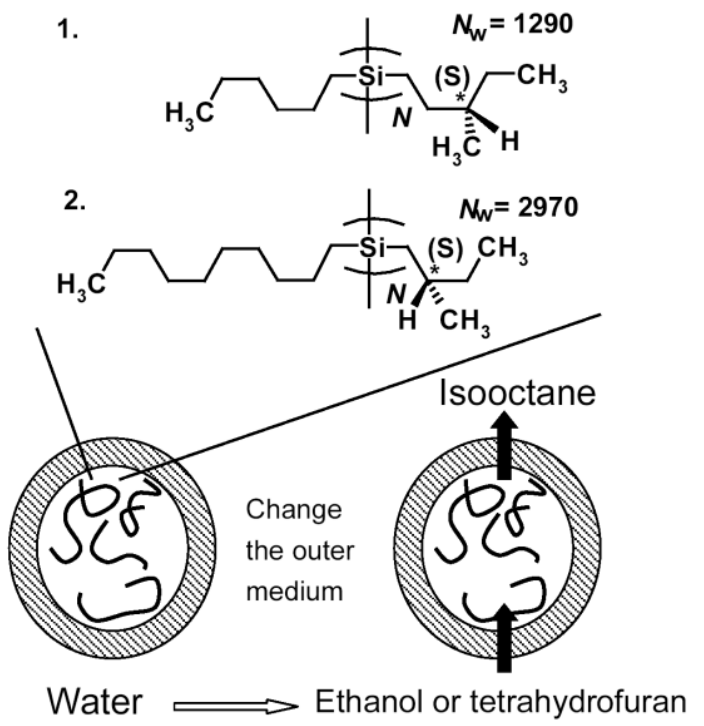

Figure 1.

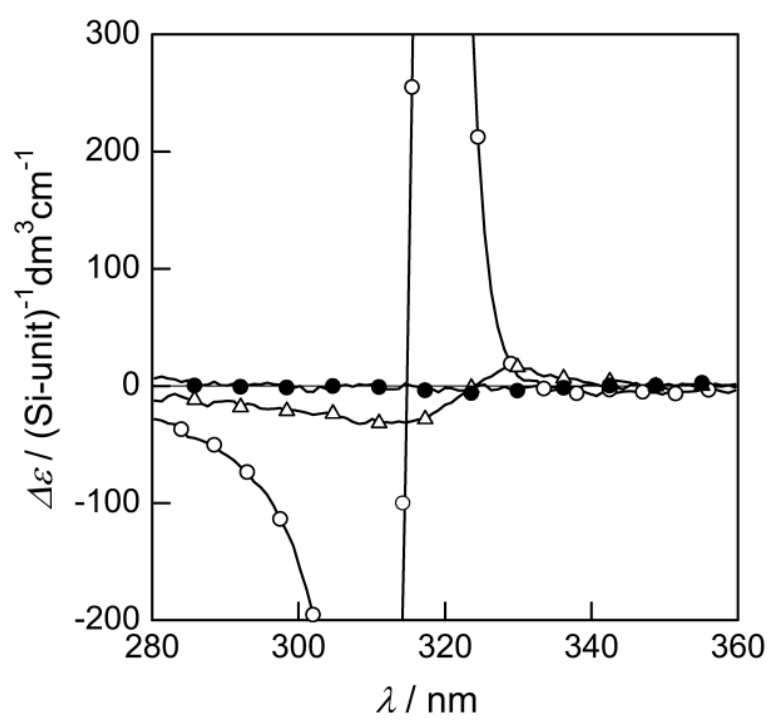

Figure 2

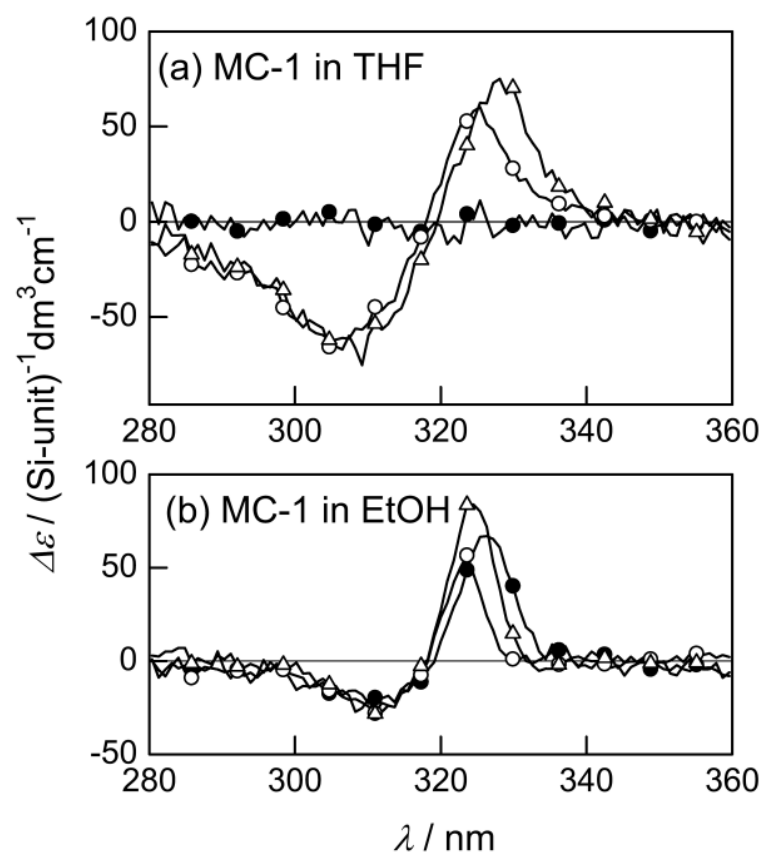

Figure 3

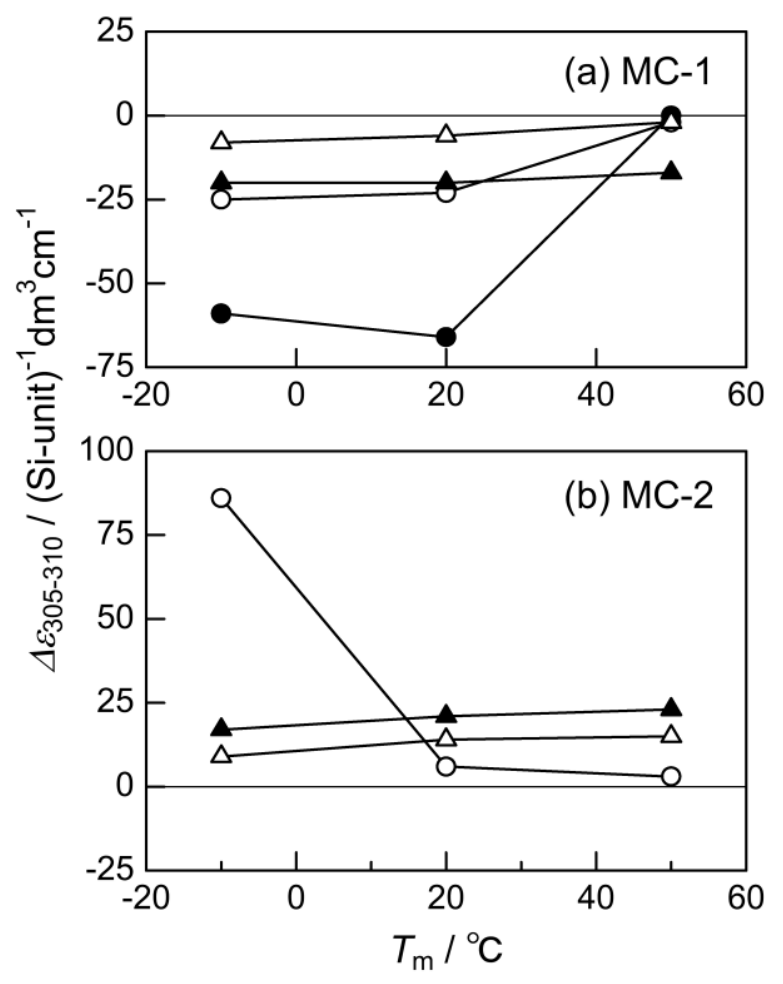

Figure 4 